\title{
Towards elimination of Lymphatic Filariasis in Kenya: Improving advocacy, communication and social mobilization activities for mass drug administration
}

\section{Lydiah W. Kibe ( $\square$ lkkibe@yahoo.com )}

Kenya Medical Research Institute https://orcid.org/0000-0001-8500-8500

Bridget W. Kimani

KEMRI- Eastern and Southern Africa Centre of International Parasite Control

\section{Collins Okoyo}

KEMRI-Eastern and Southern Africa Centre of International Parasite Control

\section{Wyckliff P. Omondi}

Kenya Ministry of Health-Division of Vector Borne and Neglected Tropical Diseases

Hadley M Sultani

Ministry of Health-Division of Vector Borne and Neglected Tropical Diseases

Doris W. Njomo

KEMRI-Eastern and Southern Africa Centre of International Parasite Control

\section{Research Article}

Keywords: Advocacy Communication and Social Mobilization, Lymphatic Filariasis, Mass Drug Administration, Neglected Tropical Diseases, Kenya

Posted Date: May 10th, 2021

DOI: https://doi.org/10.21203/rs.3.rs-477042/v1

License: (9) This work is licensed under a Creative Commons Attribution 4.0 International License. Read Full License 


\section{Abstract}

Introduction Understanding challenges affecting the implementation process of Mass Drug Administration for Lymphatic Filariasis (MDA for LF) elimination programmes is critical for successful implementation of similar interventions. The sub-Saharan Africa (SSA) region records the second highest prevalence of the disease and subsequently several countries have initiated and implemented MDA for LF. A major pillar in the Kenya Neglected Tropical Diseases (NTD) breaking transmission strategy of 2019 -2023 is that of intensifying advocacy, coordination and partnerships in NTD control and elimination. The purpose of this study was therefore to explore views and experiences of stakeholders and health workers on ways of improving Advocacy, Communication and Social Mobilization (ACSM) activities of MDA for LF programmes through participatory approaches in Kilifi County, Kenya.

Methods Two wards were purposely selected in Kaloleni sub county, Kilifi County where there was an average treatment coverage of $56 \%$ in $2015,50.5 \%$ in 2016 . Qualitative data collection methods were employed which included participatory meetings with county stakeholders to understand their views, experiences and suggestions on how ACSM strategies can be improved in MDA for LF. Twelve In-Depth Interviews (IDI) were conducted (six with opinion leaders and six with Community Health Extension Workers (CHEWs) and two Semi structured interviews (SSIs) were held with county and sub-county coordinators involved in MDA administration. The aim was better understanding their perceptions of the NTD program about ACSM, challenges to ACSM strategies, and ways to improve the strategies for ACSM in MDA for LF. Data was organized and classified into codes and themes using QSR NVIVO version 12.

Results The study observed a low participation of stakeholders in ACSM activities of MDA for LF and identified potential areas for stakeholders' involvement to strengthen the activities. Challenges hindering effective implementation of ACSM activities included late delivery of Information Educational and Communication (IEC) and few IEC materials, insufficient funding, inadequate time allocated to reach to the assigned households with messages, messaging and packaging of information for dissemination and vastness of the area. Also, highlighted were challenges with morbidity management and disability prevention services. The stakeholders recommended innovative strategies and techniques to improve ACSM activities.

Discussion and Conclusion The results of this study show key challenges to ACSM implementation of MDA for LF. Implementers need to pay attention to these challenges to enhance effectiveness of MDA in accordance to the Kenya NTD breaking transmission Strategy. ACSM efforts in MDA for LF control and elimination should be linked with overarching efforts to mainstream partnerships and coordination in control and elimination.

\section{Background}

Lymphatic filariasis (LF) has been recognized as a global public health problem affecting close to a billion people in most low resource settings(1). Sub-Saharan Africa (SSA) reports a substantial proportion 
of this burden, thus resulting in huge economic losses and disability due to the disease (2-4). To eliminate LF, the World Health Organization (WHO) recommends implementation of mass drug administration (MDA) in endemic countries, for a period of at least five years, with consistent high drug coverage levels above $65 \%$ of the population at risk (5).

In Kenya, LF is endemic in all the six counties of the coastal region along the Indian Ocean from Lamu County in the north to Kwale County in the south bordering northern Tanzania where ecological and entomological factors are suitable for its transmission (6). The Kenyan Ministry of Health (MoH) launched the LF elimination programme in 2002 in the then Kilifi District and later scaled it up in Malindi and Kwale Districts in 2003. In 2011, Tana River and Lamu counties were included while Taita Taveta and Mombasa counties were included in 2015 and 2016 respectively to achieve a 100\% geographical coverage. Following LF transmission assessment surveys in 2015, a recommendation was made to have additional MDA in counties of Kilifi, Kwale and Lamu as Circulating Filarial Antigen (CFA) showed overall prevalence of between $1.3 \%$ and $<1.7 \%$ (7). The MDA implementation campaigns for 2016-2019 was not interrupted by budgetary, technical and administrative challenges as was the case in the previous campaigns.

MDA for LF programme is under the Division of Vector Borne and Neglected Tropical Diseases, (DVBNTD) in the Kenya Ministry of Health. The implementation is guided by the Kenya NTD breaking transmission strategy 2019-2023. The plan is to expand MDA coverage, implement Water, Sanitation and Hygiene (WASH) interventions and implement Behavior Change Communication (BCC) as a comprehensive package (8). MDA implementation is done through the County and Sub-county health departments for a period between three and five days every year. Community Drug Distributors (CDDs) administer to all persons aged two years and above, an annual dosage of diethylcarbamazine citrate (6 $\mathrm{mg} / \mathrm{kg}$ ) and albendazole $(400 \mathrm{mg})$ through door to door strategy. They also conduct sensitization and awareness creation activities, through provision of information, education and communication materials to community members. The materials which include posters, pamphlets and banners are provided by the National NTD programme through county NTD coordinators. Implementation is funded by donors through the National NTD programme team who supervise the activities. Between 2016-2019, the MDA for LF programme reported national drug coverage levels of $70 \%$.

Given the multiple challenges to achieving high treatment coverage in community-based programs, it is important to identify and evaluate specific strategies and techniques that may have utility in increasing or sustaining high coverage. A systematic review by Silumbwe et., al has summarized the factors that shape implementation of MDA for LF in sub-Saharan Africa (9). One key highlight in the review was creation of partnerships and collaborations which was essential in sustained and continued implementation especially in ACSM activities. On the other hand, studies have found out that lack of partnerships and collaboration and a top down approach limit the involvement of partners and stakeholders (10). Planning for MDA implementation in Kenya is carried out at three levels - National, County and Sub-county. The national NTD division develop implementation plans and share with the county NTD coordinators for implementation at the county level and sub-county levels. Although counties make plans and these plans 
are included in their annual workplans no funds are allocated for the activity. Therefore, MDA implementation activities are solely supported by the funds from external donors through the National NTD division. These funds are not enough and counties are expected to mobilize for resources to cater for the activities planned.

Previous studies have reported challenges that negatively influence access to MDA for LF. Some of these studies highlight challenges such as; low knowledge of LF transmission, myths and misconceptions about the drugs - drugs are for family planning, fear of side effects, low perception of risk, timing of the campaigns (11) which can be addressed through effective ACSM activities. During MDA campaigns, IEC materials in form of leaflets, posters, brochures, banners and T-shirts are designed and produced at the national level and delivered to the counties. The posters and banners are posted in selected places such as the health facility, shopping centers, while pamphlets and brochures are given to the CDDs who also receive T-shirts as references and identification when conducting health education in the community. However, few studies have reported the challenges to ACSM activities in MDA for LF. This study explored the views and experiences of stakeholders and partners on social mobilization and awareness creation for MDA in the LF programme. The result of this study will help improve the quality of health messages through participation of communities and other stakeholders during preparation, development and dissemination. Consequently, this would help increase MDA access and reduce misconceptions through targeted strategies and techniques that are effective and culturally sensitive ACSM activities as a component of LF elimination in Kilifi County, Kenya.

\section{Methods}

\section{Research Design}

This qualitative study used a mix of qualitative methods including stakeholders' analysis using Venn diagrams, in-depth interviews with opinion leaders and health workers, and semi structured interviews with NTD coordinators at the county and sub-county level. The purpose was to explore the views and experiences of different players in ACSM activities for MDA in the LF programme and make recommendations for improvement.

\section{Study Setting}

The study area has been previously described by Njomo et.,al $(12,13)$ and Kusi C et.,al (14). Briefly, Kilifi County has a population of $1,109,735$ and covers an area of $12,245.90 \mathrm{~km}^{2}(15)$. The County is located north and northeast of Mombasa, the second largest town in Kenya [14]. Administratively, the County is made up of 7 sub-counties: Kilifi North, Kilifi South, Kaloleni, Rabai, Ganze, Malindi and Magarini. The County is endemic for LF caused by Wuchereria bancrofti and has a prevalence of filarial antigenaemia of $<1.7 \%$ and a mean microfilarial density of $<25 \mathrm{MF} / \mathrm{ml}(7)$. The current study was conducted in Kaloleni sub-county which has a population of 159,739 (15). Two wards i.e. Kaloleni which has a population of 41,689 of which an average of $36.8 \%$ is urban (15) and Kayafungo with a population of 22, 
250 people of different ethnic background formed the study area. The residents mainly belong to the Mijikenda ethnic group, which is a Bantu group comprising of nine sub-groups with a majority (45\%) being Giriama. The main form of livelihood within this community is subsistence farming. Based on the 2015 and 2016 MDA Programme data (MOH, Kenya,) Kaloleni and Kayafungo wards were selected purposively for the study. In 2015, Kaloleni ward achieved an average treatment coverage of $58 \%$ and Kayafungo, $54 \%$ and in 2016, Kaloleni $62 \%$ and Kayafungo $39 \%$ all below the recommended minimum treatment coverage of $65 \%$.

\section{Data Collection Procedures}

\section{Stakeholders Analysis}

Two meetings were held - one with county and one with sub county level personnel at the county and the sub county level. The meetings' aim was to share the objectives of study and receive participants' suggestions on how future MDA for LF programme could be improved. The NTD coordinators at the county and sub-county invited participants. At the county level, the meeting was attended by twenty-nine participants who included County Health Management Teams (CHMT), partners representing religious groups, Non- Governmental organizations, Governor's office representative, media houses, education and other government ministries, provincial administration and youth and women groups representatives. The one-day meeting was officially opened by the County Health Minister and moderated by the County NTD coordinator. Minutes of the meeting were taken during the meetig. The Sub county level meeting was attended by twenty-two participants who included Sub - County Health Management Teams (SCHMT), CHEWs, health facilities in charges, partners representing religious groups, non- Governmental organizations, area chief, youth and business community representatives. The one-day meeting was officially opened by the Sub County Health Officer and moderated by the Sub - County NTD coordinator. Minutes of the meeting were taken during the meeting.

Venn diagram, a visualization and participatory tool, was used with the participants to determine the closeness of various stakeholders / partners to MDA for LF campaign and their levels of involvement in ACSM activities. The further a stakeholder or partner is from the centre of the circle the lower the level of involvement. The size of the circle depicts their perceived importance in ACSM activities. All the stakeholders and partners identified were perceived as very important in ACSM activities of MDA for LF.

\section{In-depth interviews with Opinion Leaders (OL)and Community Health Extension Workers (CHEWs)}

A total of twelve in-depth interviews (IDIs) were conducted; six with Opinion Leaders (OL) and six Health Workers (HW). Opinion leaders comprised of chiefs, village elders, business owners, teachers while health workers comprised of Public Health Officers, CHEWs, Nurses, Community Health workers. The purpose was to better understand their perceptions of the NTD program about ACSM activities, challenges to successful ACSM implementation, social mobilization strategies, and ways to improve ACSM for MDA. The interviews were expected to help shed light on strategies and ways of improving ACSM strategies for 
improving access to MDA activities in the area. The IDIs were tape recorded with permission from all participants.

\section{Semi-Structured Interviews}

Two semi-structured interviews were conducted with NTD coordinators at the County and sub- county levels to generate information on previous processes of MDA and preferred processes, barriers affecting access to information and awareness creation and existing opportunities for improved ACSM activities.

\section{Quality Control}

To ensure data quality and optimization, research assistants were recruited from the community, with form four level of education and above. They received a week-long training covering qualitative data collection methods, ethical procedures, interviewing, note taking, transcription and translation. Interview guides were translated from English to Kiswahili and Kiswahili to English to reconcile discrepancies and differences. Field assistants were trained and supervised by experienced qualitative social science researchers. All issues emanating from interviewing and data capture were discussed with the research assistants and resolved in the field. After interviews field assistants reviewed their notes and added to any gaps observed. All recordings were coded and uploaded to the computer. The recordings were transcribed into English and typed in Ms Word at the end of interviewing sessions. The researchers supervised transcription process to ensure accuracy and consistency between recording and transcription.

\section{Data Processing and Analysis}

Audio recordings of the IDIs were transcribed immediately following the discussions, then translated from Swahili to English as appropriate. Transcripts were assigned unique identifiers such as IDI-KYF-OL-002; SSI_NTDC_01 etc. Field notes were incorporated in the written transcripts as additional data. The semistructured interviews were typed and saved in MS word. All documents from SSIs, IDIs and minutes of meetings were reviewed in detail then imported to Nvivo 12 Plus software (16) for further processing and analysis. Deductive analysis was used to categorize codes based on the study objectives. Four main themes emerged as follows: (a) Potential of stakeholder's involvement and participation in resource mobilization for MDA delivery with a focus on ACSM activities, (b) Challenges affecting effective implementation of ACSM activities in MDA for LF, (c) The need for innovative approaches and strategies to improve ACSM preparation, development and dissemination and (d) Challenges with morbidity management and disability prevention services. Preliminary findings of the study were presented to the stakeholders at the county level to help improve on the MDA activities. Quotes from participants were used to support the themes.

\section{Results}


The results are presented with the relevant verbatim quotes according to the four thematic areas that emerged from the data. These four thematic areas were: challenges affecting effective implementation of ACSM activities of MDA for LF; Potential of stakeholders' involvement and participation in resource mobilization for MDA delivery with a focus on ACSM activities and; the need for innovative strategies and techniques to improve ACSM preparation, development and dissemination and finally challenges with morbidity management and disability prevention services. Whilst data were collected across various participant categories, no major differences in the discussions were noted. Each of the theme is discussed below.

\section{Challenges affecting effective implementation of ACSM activities of MDA for LF}

Stakeholders discussed the progress made by Ministry of Health Kilifi county towards ACSM activities of MDA for LF elimination. They shared life experiences. It was agreed that the county had made good progress noting that there was a significant increase in knowledge on LF over the last decade, since 2002 when the programme was launched in the county. It was noted that despite efforts made by the national NTD division in soliciting funds and materials to support ACSM activities, the level of awareness was still low. Arguments emerged in relation to this issue across the partners. On the other hand, it was similarly noted that the progress was too slow and inadequate for improving knowledge and demystifying myths on LF transmission. While ACSM is important in demystifying myths and misconceptions about the disease, the drugs and fears about side effects, many issues emerged affecting its effective implementation. They cited insufficient knowledge on the transmission cycle which lead to myths and misconceptions, individual decision not to take drugs, pressure to meet targets and vastness of the area compounded by poor terrain and houses being far apart. Nonetheless, CDDs who are expected to walk to the assigned household were not able to reach out to all the households with MDA messages. Failure to address these issues could affect uptake of drugs by the target communities. Each of these issues is elaborated below with selected quotes.

\section{Insufficient knowledge on the transmission cycle thus perpetuating myths and misconceptions}

Participants in IDIs and stakeholders' meetings reported that inadequate knowledge on the LF transmission cycle and drugs administered during MDA for LF had perpetuated myths and misconceptions. Below are some extracts from participants:

...information is not adequate; simply because, mostly we call people in meetings for awareness creation in social halls, but not all people come to these meetings and forums, maybe they are employed somewhere or maybe are struggling for their daily bread, so they do not come to the places where awareness is done, so that is the problem (IDI-KLN-OL-003)

...LF is a silent disease. You only see the manifestation. The symptoms are not related to LF eg fever. The community is not aware. For us to convince them to take drugs, some do not relate it with transmission cycle. They relate it to witchcraft (SSI_NTDC_01) 
...there are several people in the community who still say the drugs are for family planning. And family planning you know it's a choice, so people were saying you were told to do family planning you refused, that is why the government have come with these drugs so that when you take them you will not bear children anyone. Men will not be able to produce children. Now, those things came up because they didn't get enough awareness, they were just told these drugs are for swollen limbs and swollen genitals so they thought they were being told that so that they could take them (IDI-KYF-OL-001)

\section{Individual decision not to take drugs}

Several issues were cited as influencing individual decision to comply with taking the drugs. Participants in IDIs indicated that some residents would accept to be left with the drugs and promise to take them later which in most cases they did not. Reasons cited included literacy levels, low perceived benefits of the drugs, perceived beliefs and attitudes towards the drugs. Below are selected comments from the participants interviewed:

... during mobilization and sensitization, they will assure you that they will have understood and that they will take the drugs but refuse to take the drugs during the MDA day. Others will receive the drugs but fail to consume in your presence saying they will take the drugs after a meal and you know you will not be there to witness and confirm they have taken. It is hard because you know you cannot force an adult person or even know their intention (IDI-KLN-HW-002)

..... there was one person I asked, despite the rest taking the drugs, why are you not willing he replied that because he does not know what the drugs are for, then he could not accept but promised to take them next time (IDI-KLN-OL-004)

.... many people are illiterate, they have their own beliefs concerning the drugs (IDI-KYF_HW_001)

\section{Pressure to meet set targets}

The CDDs were assigned each 500 households to provide awareness sessions before and during the MDA campaign. The MDA exercise takes five days (two days awareness and three days for drug administration. Opinion leaders who sometimes accompany CDDs during the campaign confessed that CDDs lack time to create awareness and to persuade residents to take drugs owing to the high target during the campaign and vastness of the area.

...if you probe for reasons why a person does not want to take drugs, you will not cover the assigned households... You see such people if you probe they say it's just within themselves. And if you probe more we delay and we shall not cover the assigned households (IDI-KLN-OL-004)

...It was like it did not reach all the people .... the area is so vast. If you have visited Kayafungo, the area is so vast therefore it did not reach everyone (IDI-KYF-HW-001)

The IEC materials are few, not in the native language and they are delivered late 
The IEC materials are important aids in creating awareness for MDA campaigns. During the interviews with county and sub-county NTD coordinators and CHEWs it was reported that the materials were delivered late, were few and usually in Swahili and English instead of the native language, Giriama. Additionally, the materials are delivered during the time drugs are delivered to the counties a few days before the drug distribution exercise which gave CHEWs and CDDs limited time to conduct awareness and sensitization sessions. Examples of extracts from the transcripts are given below.

We receive the materials late. They are delivered at the county and we should organize to collect them. Sometimes, they do not arrive at the sub-county (SSI-SCNTD-01)

The main challenge is that those IEC materials arrive late. They are delivered at the county headquarters a week before the exercise and they must be transported to the sub-county before they are distributed to CDDs (IDI-KLN-HW-001)

Posters are good because when the community see pictures they understand, but the problem is posters are always very few like we receive 3 posters and you are allocated about 12 villages (IDI-KLN-HW-002)

The IEC materials are usually in Swahili and CDD pass the messages in the local dialect. This means they translate them to their understanding causing delays in mobilization activities (SSI_NTDC_01)

The one day allocated for the training is not enough to cover the content. We focus mostly on how drugs are dispensed and reporting tools. We usually do not cover the content in the IEC but we ask the CDDS if they have issues during mobilization to inform us (IDI-KYF-HW-003)

\section{MDA Planning, implementation and follow-up}

Although development of IEC materials was executed by the National NTD office, the county and subcounty officers recommended that if given the responsibility, they could help on messaging and development of IEC materials as they understand their communities better. The county NTD programme depend on the national NTD programme for support.

The MDA activities are perceived as the national government activities and therefore most planning and other related activities are done at the national level. The county and sub-county levels usually feel left out. We could be allowed to organize the, messaging and development of IEC materials that are appropriate to our communities (SSI - CNTD_01)).

Both the county and sub-county coordinators as well as health workers interviewed acknowledged that supervision and follow-up of ACSM of MDA for LF was not sufficiently carried out due to low funding.

We plan for MDA activities and even include it in the Annual Work Plans (AWP) for the county (Kilifi). Consequently, this is included in the budget. But funds are never allocated for the activity (SSI_NTDC_01)

\section{Potential of stakeholders' involvement and participation in resource mobilization for MDA delivery with a focus on ACSM activities}


The participants observed that Kilifi county had many stakeholders but most were never utilized or minimally involved to champion access of MDA medicines and ACSM to communities they serve. The meeting participants recognised and appreciated the importance of each stakeholders and partners, as shown in the size of the circle in Figure 1. They also identified their level of involvement in ACSM as shown in Table 1. They agreed that apart from identification of stakeholders, they needed to be actively involved in joint planning, directed messaging, communication and sensitization to enhance uptake of medicines in the communities. Strengthening the role of stakeholder participation was therefore identified as crucial in resource mobilization thus improving awareness and information about MDA and LF. Below are some extracts from stakeholders' meetings:

You see there are many stakeholders and partners here. The problem is that we are not involved in this activity (referring to MDA programme). If we can be informed early, we can always support with whatever one has (Participant in the stakeholders' meeting - Kilifi County)

There is a lot that the stakeholders and partners can participate in if they are involved early. We can chip in providing resources. Letters can be sent to us requesting for assistance and I am sure most of us here will be willing to support the MDA with fuel, umbrellas, gumboots, airtime and other things that officers and CDDs might require improving coverage of MDA (Stakeholders' meeting - Kilifi)

In addition, we can participate in creating awareness to our congregations and informing them the importance of taking the medicines (Religious leader - Representative-Stakeholders' meeting - Kaloleni)

However, it was noted that a few stakeholders including schools through the Ministry of Education, State Department of Social Protection and State Department of InteriorServices and Co-ordination of National Government were involved mainly in social mobilization activities such as informing the residents about the dates of MDA activity.

..the county has pledged support. We have had increased advocacy and many sectors, departments and ministries have been involved. They include State Department of Social Protection, in advocacy and Ministry of Education through schools (SSI-NTDC-01)

\section{The need for innovative strategies and techniques to improve ACSM preparation, development and dissemination}

During the stakeholders meeting, there were suggestions for the need to provide more information about the MDA and health education through a variety of channels for improved community mobilization and compliance. Stakeholders suggested channels such as: the media through radio talk shows; public address system and road shows; focused meetings with women groups, youth groups, churches and mosques. They also suggested that messages should be simple, easy to understand and translated / disseminated in the local language to enable community members better to understand the importance of MDA for LF. Road shows involve crisscrossing the whole village, announcing the MDA from a truck 
equipped with loud speakers, and stopping where there were gatherings to distribute information brochures/leaflets and answer questions about the treatment.

Health education is very important in this exercise. We have used focused meetings, road shows and the media like Lulu fm in other programmes and the reception has been very good. (Stakeholder attendee Kilifi county).

\section{Community meetings (Barazas)}

Community meetings, barazas were used to create awareness. These were called by community leaders such as the chiefs and assistant chiefs. In these meetings, community members were informed about MDA for LF exercise and encouraged to participate as well as inform others about the programme. The community meetings were however stated not to be among the best awareness creation platforms because some community members absconded them for lack of incentives.

Community members do not attend these meetings the way they attend when we are providing them with free food (Stakeholder attendee - Kilifi county).

Importantly, the community meetings could be enhanced by attendance of health officials to educate residents about MDA for LF including why it is important to take the drugs, demystify myths and misconceptions concerning the disease and the drugs, side effects and answer technical questions from residents.

The barazas are important and residents can be encouraged to attend when they hear there are health officials in attendance to give them more information about the disease and the drug distribution exercise (DI-KYF-OL-002)

Some participants especially the opinion leaders felt that door - to - door awareness creation strategy was still the best. This was preferred as it allowed a face to face communication with the household members. But sensitization was only assigned one day during the implementation process. This therefore made it tedious, time consuming and only a few households could be reached.

.. door to door is the best strategy, because if you schedule a meeting not all people shall come for the meeting and it allows a face to face interaction (DI-KLN-OL-004)

\section{Mobile phones using WhatsApp and radio programmes}

Stakeholders suggested the need to use innovative awareness creation strategies and techniques to reach as many people as possible. They proposed the use of mobile phones to send messages about MDA for LF in areas with a local network through social media platform such as whatsApp groups. Additionally, they suggested that use of local radio stations such as Kaya FM and Lulu FM would help inform people in the local language about the programme especially in the rural areas. Once the community is made aware of the program, they could easily plan their activities and avoid missing the 
awareness teams. It was further suggested that engaging health officials knowledgeable with LF to discuss with community members on radio programme would also help create understanding and combat any negative beliefs and myths regarding the drugs and the disease.

"... we could also use mobile phones like a WhatsApp group. Most of us have WhatsApp groups with many members from churches and mosques. If we could get simplified messages from the health officials, we could send it to our members for quick dissemination. [Stakeholders - chairman Faith Based Organization representative).

\section{Challenges with morbidity management and disability prevention services}

Most of the stakeholders recounted the suffering that LF patients had to go through in their daily lives within the communities. They suggested that whilst MDA was meant for prevention, there was a need to hasten prevention services such as surgeries to those with chronic manifestations of hydrocele. It was reported that the MMDP programmme was started and identification of the patients was carried out. But, challenges were reported which hampered its effective implementation.

... at the planning stage about 550 operations were intended to have been done. Currently over 100 are conducted. But, several challenges were encountered. Among them, functional theatre to execute the surgeries, wards to admit patients after surgeries and personnel (Kilifi Stakeholders' meeting attendee)

Again, patients refuse to be registered when approached fearing surgical procedures saying that they are old and the procedure may lead them to early death.

\section{Discussion}

The present study formed part of a larger study that aimed to address barriers of community participation and access to mass drug administration for lymphatic filariasis elimination in Coastal Kenya. The results of this study identified several challenges affecting effective implementation of ACSM activities for MDA campaigns, potential for stakeholders' participation in ACSM activities and importantly highlighted the need for innovative strategies and techniques during preparation, development and dissemination.

There were clearly several challenges affecting social mobilization and awareness of MDA activities for LF. A low involvement of stakeholders and partners, CDDs pressure to meet targets, vastness of the area, limited time allocated for ACSM activities and a few and inappropriate IEC materials were cited as major challenges affecting effective implementation of ACSM activities during MDA for LF. These challenges need to be addressed if the Kenyan programme is to advance towards elimination of lymphatic filariasis. Kusi et.,al 2020 also reported that low social mobilization and awareness for MDA lead to low knowledge of transmission cycle contributing to misconceptions about the LF drugs increasing residents refusal to take drugs (14). 
The current study observed that stakeholders were minimally utilized to champion MDA for LF activities in the county, sub-county and community level as shown in Table 1 and Figure 1.

However, stakeholders' involvement was emphasized as an important factor in improving MDA implementation especially in social mobilization and awareness creation activities. The stakeholders identified areas that they could be effectively involved in for improved social mobilization and MDA activities. The following three key roles were identified: social mobilization and awareness, messaging and dissemination of information and resource mobilization were suggested to enhance their participation. Studies have shown that local partnerships are important in shaping participation and implementation as they provide a platform for building social capital, respectful relationships, engender trust and sustain community support towards the MDA for LF programme $(17,18)$. A study by Silumbwe et.al 2019, reported that key stakeholders such as civic leaders promoted stakeholders' buy-in, political good will and motivated the community members to participate in MDA for LF (19). Importantly also, strategic international collaborations have been seen to equally contribute to facilitating participation in MDA for LF (20). Stakeholders and partners in this study were willing to support the MDA for LF with resources such as gumboots, umbrellas, airtime, fuel for officers' moto bikes and fuel for vehicles used in the campaign. Resource mobilization from stakeholders and partners will be necessary as this will increase supervision and CDDs motivation which has been reported as barriers to improved MDA access (12-14). Implementers have therefore to pay attention to such opportunities and start conversations that will lead to improved access.

The willingness of stakeholders and partners to support MDA activities with fuel for moto bikes and airtime to health officers and the CDDs would facilitate movement in the vast villages. This will be of great help to CDDs as it will enable them to reach most households with messages about benefits of taking the drugs and side effects. On the other hand, the support from stakeholders will improve on field supervision by the health teams and strengthen communication. Low community sensitization and lack of supervision have been cited as issues that reduce motivation to CDDs (21). Krentel et al., 2017 emphasize on the importance of community engagement processes that promote participation being essential in achieving sustainable and successful implementation of MDA for LF (22).

The study also observed several challenges with IEC production, messaging, delivery and dissemination. Specifically, the following barriers were identified: delays in delivery of IEC materials from the national NTD to the CDDs through the counties and sub-counties, packaging and messaging in the language that is not commonly spoken by residents, production and delivery of few IEC materials among others. The materials such as posters, pamphlets and booklets were produced and delivered to the county NTD offices but were very few and not in the local language, Giriama. Mass drug administration should be preceded by proper mobilization activities for its successful implementation. Delays in delivery of IEC materials to the counties and sub-counties and provision of few IEC materials to CDDS meant insufficient awareness to residents and few social mobilization activities. This compromised resident understanding of the benefits of the drug and participation in the MDA campaign, resulting in reduced treatment coverage. 
The shortfall and delay of delivery of IEC materials meant there was inadequate awareness creation to the community members. Again, the CDDs had to summarize and simplify the messages on their own by translating them to the local dialects. With the CDD level of education, the intended message might have been lost or distorted while summarizing and translating into the local dialects. Again, the one day allocated for awareness creation was too short to reach the assigned (500) households with MDA messages. An opinion leader who accompanied CDDs confessed that they hurriedly created the awareness and could not sufficiently answer to the issues that residents inquired due to time constraint. Considering that most CDDs have low level of education, programme planners should ensure that the IEC materials are delivered early enough - a week before the MDA, are in local dialect and that more time is allocated for social mobilization and training to allow the CDDs to reach households with MDA information. Literature cite that identifying barriers that persist across different health behaviours such as lack of time (due to family, household and occupational responsibilities), access issues (to transport and facilities), entrenched attitudes, restrictions in the physical environment and lack of knowledge can inform the design of tailored interventions for the community(23). Intensified IEC activities, including the development and distribution of posters, flyers, leaflets, brochures, and radio and TV broadcasting of health messaging in the local language to promote awareness of drug distribution activities, provide health education, and promote behaviour change, to increase treatment coverage (24-26). Enhanced ACSM activities of MDA for LF in Urban Kenya saw an increase in coverage in experimental clusters of $72.2 \%$ compared to $70.4 \%$ in control clusters with standard ACSM activities (25).

Implementing public health interventions, such as MDA, in the community setting is complex and challenging, because there are numerous cultural and individual factors that directly or indirectly influence treatment delivery (27). In this regard, creating awareness and health education plays an important role in facilitating participation and subsequently increasing uptake of drugs in MDA for LF. It helps to transform the mind-set of the community through empowering them with information about the relevance of MDA. For such a transformation to occur, it will be imperative that sufficient time is allocated for awareness creation and health education, IEC materials should be translated into local dialects and innovative techniques such as use Whatsapp groups are utilized when creating awareness. These recommendations are consistent with findings of a study conducted in another part of sub- Saharan Africa (24). A study from Sierra Leone showed that use of innovative and more "modern" sensitization techniques, enabled the reaching of individuals and institutions that had otherwise been unaware of MDA for LF (28). Two Nigerian studies further reported that conducting Knowledge Attitude and Practices (KAP) surveys enabled the MDA for LF programme to design target specific, responsive and widely accepted IEC materials $(29,30)$ while a study in Sierra Leone reported a change in social messaging strategy whereby they are working directly through the organized religious networks and traditional healers as they have greater influence over practices in the most vulnerable communities (31). The mandate of developing educational materials should be left with the local health officials and partners as they will consider their local experiences and other contextual issues of their communities. This needs to be encouraged and reinforced especially during this era of Corona Virus pandemic thus fostering community ownership $(32,33)$. 
Concerning limitations of the study, the purposive selection of participants might have resulted in selection bias. Secondly, social desirability bias may have affected the response of the participants. To minimize these limitations, different methods were used in data collection which allowed for triangulation by experienced social science researchers.

\section{Conclusions And Recommendations}

Strengthening ACSM strategies and techniques is essential for improving residents' awareness for MDA of LF. As identified in this study, a deliberate effort is required in sensitizing residents about the risk and benefits of diethylcarbamazine (DEC). In addition, MDA for LF teams will need to ensure proper planning for ACSM activities including messaging, disseminating as well as ensuring training, supportive supervision and monitoring for effectiveness implementation of these activities. Conducting needs assessment such as surveys will also be important. This will give direction on the appropriate strategies and techniques as well as information and training needs of the community members. Finally, a social ecological approach should be adopted where all sectors in the community including family, communities, institutions (local and national, government and non-governmental) and policy makers contribute in the design, development and dissemination of target specific, appropriate, responsive and acceptable ACSM strategies and techniques.

\section{Abbreviations}

ACSM: Advocacy, Communication, Social and Mobilization

CFA: Circulating Filarial Antigen

DVB-NTD: Division of Vector Borne and Neglected Tropical Diseases

CDD: Community drug distributor

CHEW: Community health extension worker

KEMRI: Kenya Medical Research Institute

LF: Lymphatic filariasis

MDA: Mass Drug Administration

NTDs: Neglected tropical diseases

WHO: World Health Organization

\section{Declarations}


Ethical clearance was received from the Kenya Medical Research Institute (KEMRI), Scientific and Ethics Review Unit (SERU) Protocol Number 3666. Written informed consent was sought from all the study participants. All the participants were adults above the age of 18 years.

\section{Consent for publication}

Informed consent was obtained from all individual participants included in the study. This study has been published with the permission of the Director General, KEMRI.

\section{Availability of data and materials}

The datasets and materials generated during the current study are available upon request from the Director General, KEMRI through director@kemri.org

\section{Competing interests}

No conflict of interest is declared.

\section{Funding}

This study received financial support from the Coalition for Operational Research on Neglected Tropical Diseases (COR-NTD) NTDSC 138D, which is funded at the Task Force for Global Health primarily by the Bill \& Melinda Gates Foundation, by the UK aid from the British government and by the United States Agency for International Development through its Neglected Tropical Diseases Program. The funders had no role in the design of this study, data collection and analyses, decision to publish or preparation of the manuscript.

\section{Authors' contributions}

DWN conceived and designed the study. DWN, LWK, WPO, CO, and BWK provided technical guidance in data collection, planning and carrying out the daily field work. DWN, LWK, CO, and BWK participated in recruitment strategies, acquisition of data, as well as analysis and interpretation of data. LWK drafted the initial manuscript. DWN revised the manuscript. All authors read and approved the final manuscript.

\section{Acknowledgements}

The authors are grateful to Department of Health of Kilifi County and Kaloleni sub-county for their technical support, partners and stakeholders for their valuable contribution during the implementation of this study. We appreciate all the participants who agreed to take part in interviews and to the field assistants for their efforts in data collection.

\section{Authors' information}

Dr. Lydiah W. Kibe: Kenya Medical Research Institute - Eastern \& Southern Africa Centre of International Parasite Control: Ikkibe@yahoo.com 
Ms. Bridget W. Kimani: Kenya Medical Research Institute - Eastern \& Southern Africa Centre of International Parasite Control: bridgetkimani@gmail.com

Mr. Collins Okoyo: Kenya Medical Research Institute - Eastern \& Southern Africa Centre of International Parasite Control: collinsomondiokoyo@gmail.com

Mr. Wyckliff P. Omondi: Ministry of Health, Kenya - Division of Vector Borne and Neglected Tropical Diseases: wyckliff.omondi@gmail.com

Dr. Hadley M. Sultani: Ministry of Health, Kenya - Division of Vector Borne and Neglected Tropical Diseases: hadleysultan@gmail.com

Dr. Doris W. Njomo: Kenya Medical Research Institute - Eastern \& Southern Africa Centre of International Parasite Control: dorisnjomo@gmail.com

\section{References}

1. World Health Organization. Global programme to eliminate lymphatic filariasis: progress report, 2017. Geneva: WHO, 2018 Contract No.: 44).

2. Hotez P.J, Kamath A. Neglected tropical diseases in sub-Saharan Africa: review of their prevalence, distribution, and disease burden. PLoS neglected tropical diseases. 2009 3(8):e412

3. Bockarie M.J, Rebollo M. Reducing the population requiring interventions against lymphatic filariasis in Africa. The Lancet Global Health. 2016;4(.3):e154-e5.

4. Gyapong J, Boatin B. Neglected tropical diseases-sub-Saharan Africa: Springer; 2016: .

5. Ndeffo-Mbah M.L, Galvani AP. Global elimination of lymphatic filariasis. The Lancet Infectious Diseases. 2017;17(4):358-9. .

6. Moraga P, Cano J, Baggaley RF, Gyapong JO, Njenga SM, Nikolay B, et al. Modelling the distribution and transmission intensity of lymphatic filariasis in sub-Saharan Africa prior to scaling up interventions: integrated use of geostatistical and mathematical modelling. . Parasit Vectors. 2015;8:560.

7. Njenga SM, Kanyi HM, Mutungi FM, Okoyo C, Matendechero HS, Pullan RL, et al. Assessment of lymphatic filariasis prior to re-starting mass drug administration campaigns in coastal Kenya. Parasites \& Vectors. 2017;10(1):99.

8. Ministry of Health. The Kenya National Breaking Transmission Strategy for Soil-Transmitted Helminthiasis, Schistosomiasis, Lymphatic Filariasis and Trachoma 2019-20233. Strategy. Nairobi: Ministry of Health, DVB-NTD; 2019 2019. Report No.

9. Silumbwe A, Zulu JM, Halwindi H, Jacobs C, Zgambo J, Dambe R, et al. A systematic review of factors that shape implementation of mass drug administration for lymphatic filariasis in subSaharan Africa. BMC Public Health. 2017;17(1):484. 
10. Dissak-Delon FN, Kamga G-R, Humblet PC, Robert A, Souopgui J, Kamgno J, et al. Barriers to the National Onchocerciasis Control Programme at operational level in Cameroon: a qualitative assessment of stakeholders' views. Parasites \& Vectors. 2019;12(1):246.

11. Krentel A, Fischer PU, GJ. W. A review of factors that influence individual compliance with mass drug administration for elimination of lymphatic filariasis. PLoS Negl Trop Dis. 2013;7(11):e2447.

12. Njomo DW, Kimani BW, Kibe LW, Okoyo C, Omondi WP, Sultani H. Implementation challenges and opportunities for improved mass treatment uptake for lymphatic filariasis elimination: Perceptions and experiences of community drug distributors of coastal Kenya. PLoS Negl Trop Dis 2020;14(12).

13. Njomo DW, Kibe LW, Kimani BW, Okoyo C, Omondi WP, Sultani H. Addressing barriers of community participation and access to mass drug administration for lymphatic filariasis elimination in Coastal Kenya using a participatory approach. PLoS Negl Trop Dis 2020;14(9).

14. Kusi C, Steinmann P, Merten S. The fight against lymphatic filariasis: perceptions of community drug distributors during mass drug administration in coastal Kenya. Infectious Diseases of Poverty. 2020;9(1):22.

15. Kenya National Bureau of Statistics. Kenya Population and housing census: Analytical report on population projections. .Available:http://www.knbs.or.ke/index.php? option=com_phocadownload\&view=category\&id=109:population-and-housing-census-2009\&ltemid=

16. Accessed 29 November 2017. Nairobi, Kenya: KNBS, 2009 Contract No.: 5th February 2021.

17. Jackson K, Bazeley P. Qualitative Data Analysis With NVivo. 3rd ed. Western Sydney University, U.K.: Sage Publications 2019

18. Malina R. physical activityand health of youth.Constanta. Ovidius University Annals. 2010;Series Physical Education and Sport/Science(Movement and Health).

19. LIESE B, ROSENBERG M, SCHRATZ A. Progmmes, partnerships, and governance for elimination and control of neglected tropical diseases. The Lancet. 2010;375(9708):67-76.

20. Silumbwe A, Halwindi H, Zulu JM. How community engagement strategies shape participation in mass drug administration programmes for lymphatic filariasis: The case of Luangwa District, Zambia. PLoS neglected tropical diseases. 2019;13(11).

21. Sodahlon YK, Dorkenoo AM, Morgah K, Nabiliou K, Agbo K, Miller R. A Success Story: Togo Is Moving toward Becoming the First Sub-Saharan African Nation to Eliminate Lymphatic Filariasis through Mass Drug Administration and Countrywide Morbidity Alleviation. PLoS Negl Trop Dis 2013;7(4).

22. Taylor M, Oliver S, Garner P. Mass drug administration for filariasis: community views and programme design influences - a qualitative evidence synthesis. Cochrane Database of Systematic Reviews. 2020(6).

23. Krentel A GM, Mallya S, Boadu NY, Amuyunzu-Nyamongo M, Stephens M, et al. Review of the factors influencing the motivation of community drug distributors towards the control and elimination of neglected tropical diseases (NTDs). PLoS Negl Trop Dis 2017;11(12).I

24. Kelly S, Martin S, Kuhn I, Cowan A, Brayne C, Lafortune L. Barriers and Facilitators to the Uptake and Maintenance of Healthy Behaviours by People at Mid-Life: A Rapid Systematic Review. PLoS ONE. 
2016;11(1):1-26.

25. Dembélé $M$, Bamani S, Dembélé R, Traoré MO, Goita $S$, Traoré MN, et al. Implementing preventive chemotherapy through an integrated National Neglected Tropical Disease Control Program in Mali. PLoS Negl Trop Dis. 2012;6(3):e1574.

26. Njomo DW, Mukoko DA, Nyamongo NK, Karanja J. Increasing Coverage in Mass Drug Administration for Lymphatic Filariasis Elimination in an Urban Setting: a Study of Malindi Town, Kenya. . PLoS ONE (2014) 9(1).

27. World Health Organization. Child Health and Development: Information, Education, and Communication 2017.

28. Omedo M, Matey E, Awiti A, Ogutu M, Alaii J, Karanja D, et al. Community health workers' experiences and perspectives on mass drug administration for schistosomiasis control in western Kenya: the SCORE Project. Am J Trop Med Hyg. 2012;87:1065-72.

29. Hodges MH, Smith SJ, Fussum D, Koroma JB, Conteh A, Sonnie M, et al. High coverage of mass drug administration for lymphatic filariasis in rural and non-rural settings in the Western Area, Sierra Leone. Parasit Vectors. 2010;3:120.

30. Richards FO, Eigege A, Miri ES, Kal A, Umaru J, Pam D, et al. Epidemiological and entomological evaluations after six years or more of mass drug administration for lymphatic filariasis elimination in Nigeria. PLoS Negl Trop Dis. 2011;5(10):e1346.

31. Hopkins DR, Eigege A, Miri ES, Gontor I, Ogah G, Umaru J, et al. Lymphatic filariasis elimination and schistosomiasis control in combination with onchocerciasis control in Nigeria. Am J Trop Med Hyg. 2002;67(3):266-72.

32. Bah YM, Paye J, Bah MS, Conteh A, Redwood-Sawyerr V, Sonnie M, et al. Achievements and challenges of lymphatic filariasis elimination in Sierra Leone. PLoS Negl Trop Dis. 2020;14(12):e0008877.

33. Alison Krentel, Margaret Gyapong, Deborah A McFarland, Olumide Ogundahunsi, Christiana R Titaley, Addiss. DG. Keeping communities at the centre of efforts to eliminate lymphatic filariasis: learning from the past to reach a future free of lymphatic filariasis International Health. 2021;Volume 13(issue Supplement):S55-S9.

34. World Health Organization. Community-based health care, including outreach and campaigns, in the context of the COVID-19 pandemic: interim guidance. World Health Organization, 2020 Contract No.: WHO/2019-nCoV/Comm_health_care/2020.1.

\section{Tables}

able 1 shows the stakeholders \& partners identified and their level of involvement in ACSM ctivities 


\begin{tabular}{|c|c|}
\hline Stakeholders \& partners identified & $\begin{array}{l}\text { Level } \\
\text { involvement } \\
\text { ACSM activities }\end{array}$ \\
\hline $\begin{array}{l}\text { Government ministries - Ministry of education, department of health, } \\
\text { Department of social services, Ministry of Interior, }\end{array}$ & High \\
\hline $\begin{array}{l}\text { Non-Governmental Organizations - Plan international, Afya Pwani, } \\
\text { Population Services International }\end{array}$ & Low \\
\hline Financial institutions: local banks; & Low \\
\hline $\begin{array}{l}\text { Local and community organizations e,g Maendeleo ya wanawake, } \\
\text { youth groups, women groups, religious and faith based } \\
\text { organizations }\end{array}$ & Low \\
\hline Media & Moderate \\
\hline Research institution - KEMRI & Moderate \\
\hline Manufacturing industries - Bamburi Cement, Mombasa Cement & Low \\
\hline Hospitality industries - hotels & Low \\
\hline
\end{tabular}

\section{Figures}




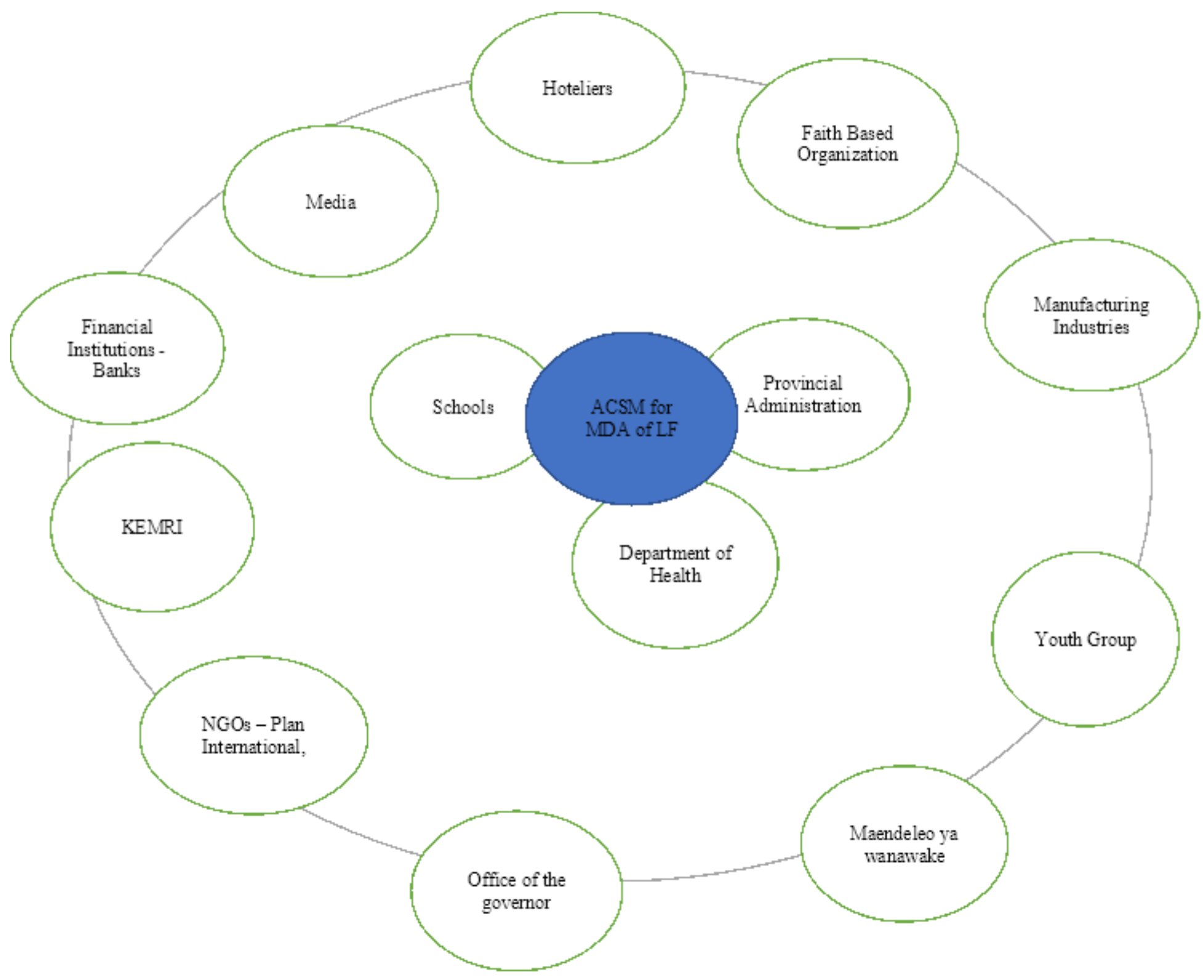

\section{Figure 1}

Example of Venn diagram showing the level of involvement in ACSM activities of MDA for LF at the county level - The big outer circle represents ACSM activities for MDA for LF - The middle of the outer circle is represented by a circle written ACSM activities - Circles close to the middle depict closeness to ACSM activities. The stakeholders that were identified as actively participating in ACSM activities are close to the middle while those that are far off from the middle were minimally engaged. - The size of the circle depicts perceived importance of a stakeholder or partner in ACSM activities. All stakeholders and partners were identified as important. Their importance was based on expected roles in ACSM activities 